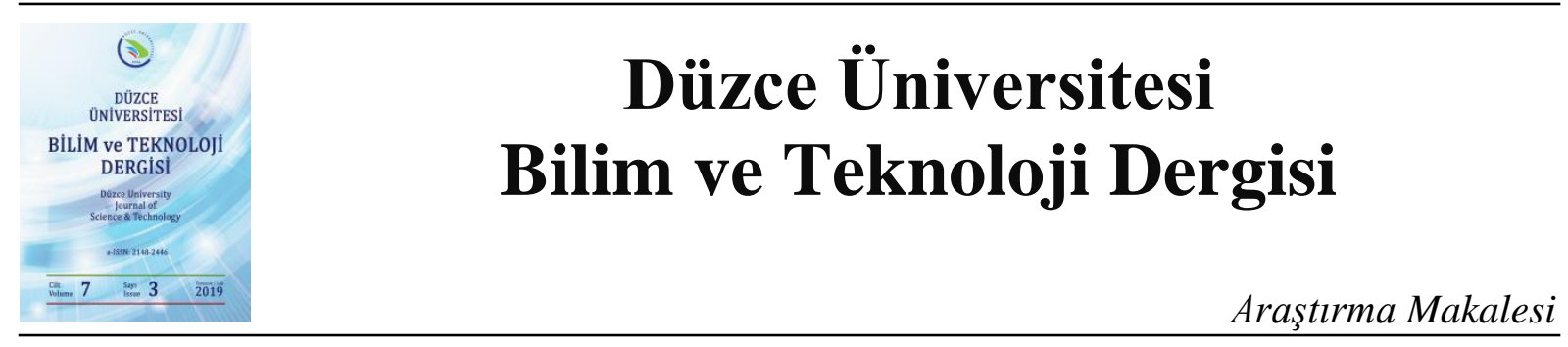

\title{
Kimyasal Spreyleme Atıksuyunun Arıtımında Elektrokoagülasyon Prosesinin Optimizasyonu: Box-Behnken Dizaynı
}

\author{
iD Murat SOLAK ${ }^{\mathrm{a}, *}$ \\ ${ }^{a}$ Çevre Mühendisliği Bölümü, Mühendislik Fakültesi, Düzce Üniversitesi, Düzce, TÜRKIYYE \\ *muratsolak@duzce.edu.tr \\ DOI : 10.29130/dubited.518579
}

\begin{abstract}
ÖZET
$\mathrm{Bu}$ çalışmada, kot pantolon üretiminde kimyasal spreyleme işleminden oluşan atıksuyun, Alüminyum (Al) elektrot kullanılarak Elektrokoagülasyon (EK) Prosesi ile arıtımı incelenmiştir. EK prosesi ile KOİ (Kimyasal Oksijen İhtiyacı) ve TÇK (Toplam Çözünmüş Katı) parametrelerinin giderimi için pH, akım yoğunluğu (A.Y.) ve elektroliz süresi (E.S.) gibi EK proses verimliliğinde önemli rol oynayan parametrelerin etkileri belirlenmiştir. Deneysel tasarımda Box-Behnken istatistiksel modeli kullanılmıştır. İstatistiksel analizler her iki kirletici için de sonuçların quadratik modele uygun olduğunu göstermiştir. EK reaktöründe KOİ ve TÇK'nın giderilmesi için regrasyon $\left(R^{2}\right)$ değerinin sirasılyla 0,95 ve 0,$99 ; R^{2}$ adj değerinin sirasiyla 0,88 ve 0,99 olduğu bulunmuştur. $R^{2}$ ve $\mathrm{R}^{2}$ adj değerlerinin 1 'e yakın olması, deney sonuçlarının ve istatistiksel çıkarımların uyumlu olduğunu ve işlem parametrelerinin etkilerinin belirlenmesinde Box-Behnken istatistiksel tasarımının etkili olduğunu göstermektedir. KOİ ve TÇK giderimi için optimum $\mathrm{pH}$ değerleri sırasıyla 5,01 ve 6,66 olarak tespit edilirken, her iki kirletici için optimum akım yoğunluğu $59 \mathrm{~A} / \mathrm{m}^{2}$ ve elektroliz süresi $29 \mathrm{dk}$. olarak belirlenmiştir.
\end{abstract}

Anahtar Kelimeler: Elektrokoagülasyon, Kimyasal Spreyleme Atıksuyu, Box-Behnken İstatistiksel Modeli

\section{Optimization of the Electrocoagulation Process in the treatment of Chemical Spraying Wastewater: Box-Behnken Design}

\begin{abstract}
In this study, the treatment of wastewater consisting of the chemical spray process in jeans production by Electrocoagulation (EC) Process using Aluminum (Al) electrode was investigated. The effects of the parameters that play an important role in the EC process efficiency such as $\mathrm{pH}$, current density (C.D.) and electrolysis time (E.T.) for the removal of the COD (Chemical Oxygen Demand) and TDS (Total Dissolved Solids) by EC process were determined. Box-Behnken Statistical Model was used in experimental design. Statistical analyzes show that the results for both pollutants match the quadratic model. The coefficient of determination $\left(\mathrm{R}^{2}\right)$ value for removal of COD and TDS in the EC reactor, was found to be 0.95 and 0.99 , and $\mathrm{R}^{2}$ Adj value was found to be 0,88 and 0,99 , respectively. Being $R^{2}$ and $R^{2}$ adj values close to 1 indicates that the experimental results and statistical inferences were compatible and the Box-Behnken statistical design was effective in order to determine
\end{abstract}

Geliş: 04/02/2019, Düzeltme: 06/03/2019, Kabul: 16/03/2019 
the effects of process parameters. The optimum $\mathrm{pH}$ values for COD and TDS removal were determined as 6.51 and 6.4 respectively, whereas the optimum current density for both pollutants was $59 \mathrm{~A} / \mathrm{m}^{2}$ and the electrolysis time was 29 minutes.

Keywords: Electrocoagulation, Chemical Spraying Wastewater, Box-Behnken Statistical Design

\section{GiRISs}

$\mathrm{K}$ ot üretim sektörü üretim prosesleri gereğince yüksek miktarlarda su tüketen bir sektördür. Üretim proseslerinin çeşitliliği ve su tüketiminin fazlalığı oluşan atıksuyun kompleks ve fazla miktarda olmasına neden olmaktadır. Denim ürün üretim süreçlerinde oluşan atıksu, yüksek KOİ ve renk içermektedir. Kot pantolon üretim süreçlerinde bir proses olan kimyasal spreyleme işlemi denim ürünün istenen özelliklerinin sağlanması adına son derece önemlidir. Kimyasal spreyleme işleminde kot pantolona sprey yardımıyla potasyum permanganat gibi kimyasal maddeler püskürtülerek eskitme, istenen rengi elde etme gibi istenen özellikler kazandırılır. Kimyasal spreyin yapıldığı kabinin arka kısmında sürekli olarak su akmaktadır. Böylelikle, kimyasal sprey tabancasından çıkan kimyasalların işletme içinde doğrudan havaya karışması ve spreyleme işlemini yapan çalışana geri gelmesi engellenerek, yıkama kabinindeki suya geçmesi sağlanır. Kimyasal spreylemede kullanılan su yoğun kirlilik içeriğine ulaştığında yenilenir. Yenilenme sürecine kadar sürekli aynı havuzlarda bekletilerek tekrar tekrar aynı su kullanılır.

Kimyasal içeriğe sahip atıksuların arıtılmasında koagülasyon [1,2], oksidasyon [3], elektrokoagülasyon [4] gibi prosesler kullanılmaktadır. Koagülasyon prosesi özellikle kolloidal kirliliğin fazla olduğu atıksularda etkin bir şekilde giderim sağlamaktadır. Oksidasyon prosesi çözünmüş organik maddelerin gideriminde etkin şekilde kullanılmaktadır. Yine kompleks ve birçok kirleticinin gideriminde etkin olarak kullanılan EK prosesi, anot, katot elektrot ve bu elektrotların bağlandığı DC Güç kaynağı ile redoks reaksiyonlarına bağlı olarak oluşan kimyasallar ile çözelti içerisindeki kirleticilerin giderildiği bir prosestir. Bu proseste, elektriksel alan varlığı ile çok küçük kirleticileri giderebilme, atıksu deşarj $\mathrm{pH}$ değerinde ayarlama gerektirmeme gibi birtakım avantajlara sahiptir. EK prosesinde ucuz, kolay temin edilebilmesi bakımından en çok kullanılan elektrot türü $\mathrm{Al}$, $\mathrm{Fe}$ elektrotlarıdır. Fe elektrodu oksitlenmeden dolayı çözeltiye renk verdiğinden çalışmada $\mathrm{Al}$ elektrodu kullanılmıştır. Al elektrodunun kullanıldığ 1 EK prosesinde gerçekleşen reaksiyonlar Eşitlik $1-3$ 'te görülmektedir [5].

\section{$\underline{\text { Anotta }}$}

$\mathrm{Al} \rightarrow \mathrm{Al}^{3+}+3 \mathrm{e}^{-}$

$\underline{\text { Katotta }}$

$3 \mathrm{H}_{2} \mathrm{O}+3 \mathrm{e}^{-} \rightarrow 3 / 2 \mathrm{H}_{2(\mathrm{~g})}+3 \mathrm{OH}^{-}$

Çözeltide

$\mathrm{Al}^{3+}{ }_{(\text {aq })}+3 \mathrm{H}_{2} \mathrm{O} \rightarrow \mathrm{Al}(\mathrm{OH})_{3}+3 \mathrm{H}^{+}($aq $)$ 
$\mathrm{Bu}$ çalışmada da kimyasal spreyleme prosesinden kaynaklanan atıksuların Al elektrodunun kullanıldığ 1 EK prosesi ile arıtımı gerçekleştirilmiştir. EK proses verimliliğini etkileyen $\mathrm{pH}$, akım yoğunluğu ve elektroliz süresi gibi parametreler KOİ, TÇK giderimine etkileri Box-Behnken istatistiksel metot kullanılarak değerlendirilmiştir.

\section{MALZEME VE YÖNTEM}

Kimyasal spreyleme ham atıksuyunun karakterizasyonu Tablo 1'de verilmiştir. Ham atıksu kot pantolon üretimi yapan bir tekstil firmasından temin edilmiştir.

Tablo 1. Ham atıksu karakterizasyonu

\begin{tabular}{ll}
\hline Parametre & Değer/Konsantrasyon \\
\hline $\mathrm{pH}$ & 7,56 \\
\hline İletkenlik & $6,43 \pm 0,2 \mathrm{mS} / \mathrm{cm}$ \\
\hline KOİ & $120 \pm 10 \mathrm{mg} / \mathrm{L}$ \\
\hline TÇK & $3,24 \pm 0,1 \mathrm{~g} / \mathrm{L}$ \\
\hline
\end{tabular}

\section{A. ELEKTROKOAGÜLASYON MODEL REAKTÖR̈̈}

EK prosesinin deney düzeneğinin şematik gösterimi Şekil 1'de görülmektedir. Model reaktör, HxBXL 85x80x80 mm olarak tasarlanmıştır. Model reaktörde kullanılan Al elektrodunun boyutları, $40 * 80 * 0,1$ mm'dir.

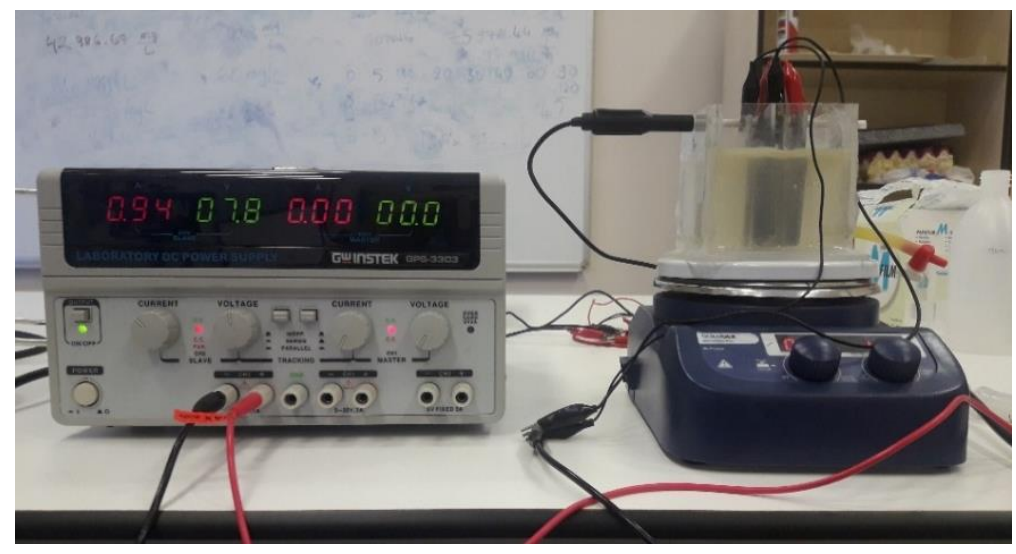

Şekil 1. EK Deney Düzeneği

\section{B. DENEYSEL CALISMALAR}

Kesikli olarak işletilen reaktöre $350 \mathrm{~mL}$ atıksu numunesi eklenerek deneysel çalışmalara başlanmıştır. Çalışmada EK prosesini etkileyen en önemli parametreler olan $\mathrm{pH}$, akım yoğunluğu ve elektroliz süresi parametrelerinin KOİ ve TÇK giderim verimine etkileri incelenmiştir. Paralel bağlantı sistemi kullanılmıştır (Şekil 2). Elektrotlar, tasarlanan elektrot bağlantı sistemine yerleştirildikten sonra elektroliz işlemine başlanmıştır. Reaktör içerisinde çökelme olmaması ve giderim veriminin yükseltilmesi amacı ile çözelti içerisindeki anyon ve katyon temasını artırmak için 200 devir/dakika karıştırma hızında sürekli olarak karıştırılmıştır. Tüm deneyler oda sıcaklığında $\left(\sim 25^{\circ} \mathrm{C}\right)$ gerçekleştirilmiştir. Sıcaklığın sabit tutulması için 1sıtıcılı banyo kullanılmıştır. Reaktörden alınan 
çıkış suyu, $0,45 \mu \mathrm{m}$ gözenek çapına sahip şırınga filtreden süzüldükten sonra parametre analizleri yapılmıştır. $\mathrm{pH}$ ayarlaması için $\mathrm{HCl}$ ve $\mathrm{NaOH}$ çözeltileri, iletkenlik ayarlaması için $\mathrm{NaCl}$ kullanılmıştır.

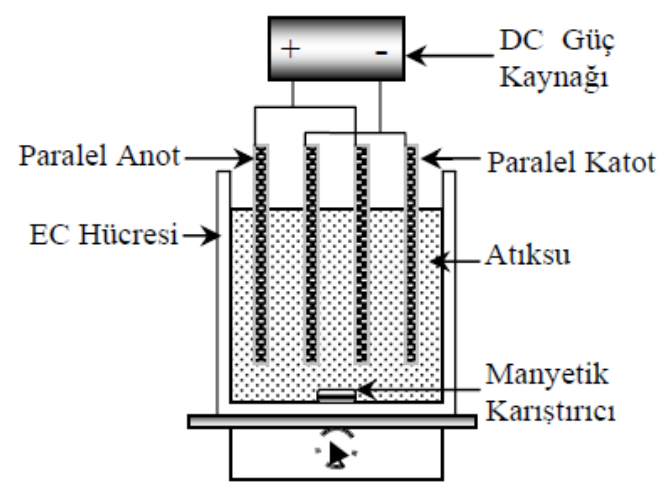

Şekil 2. Paralel Bağlantı Sistemi

\section{METOT}

Deneysel çalışmalarda, giriş ve çıkış suyu örneklerinde KOİ konsantrasyonlarının belirlenmesi için Standart Metot (5220 D) metot kullanılmıştır. pH ve iletkenlik, elektrometrik metoda (SM 4500-H+) göre Hanna cihazı kullanılarak belirlenmiştir [6]. Akım ve voltaj kontrolü Gwinstek GPS 3303 DC Power Supply (0-30V, 0-3A) model güç kaynağı ile sağlanmıştır. Karıştırma işleminde SCllogex MSH 280-Pro model karıştırıcı kullanılmıştır. pH ölçümleri Hanna HI 2211 model pH metre ile elektrometrik, iletkenlik ve TÇK ölçümleri Hach İletkenlik-TDS metre ile elektrometrik yöntem ile gerçekleştirilmiştir.

\section{ISTATISTIKSEL ANALIZ}

Deneysel çalışmaların sonuçlarının değerlendirilmesi amacıyla, Box-Behnken istatistiksel analizi kullanılmıştır (Şekil 3). Box-Behnken, dizaynı yanıt yüzey dizaynlarından biri olup, ikinci derecedir. Diğer yanıt yüzeylerine göre daha az veri girişi gerektirir.

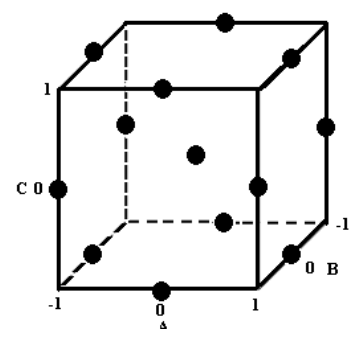

Şekil 3. Box-Behnken İstatistiksel Dizaynı

Atıksuyun pH değeri, akım yoğunluğu ve elektroliz süresi bağımsız değişkenler olarak ele alınmıştır. Box-Behnken istatistiksel analizi, Design Expert (trial) programı kullanılarak; ANOVA tablosu çıkarılarak, P, R ${ }^{2}$, F değerleri elde edilmiştir.

Dizayn tablosuna göre yapılan deneyler sonucunda bulunan KOİ ve TÇK giderim verileri kullanılarak aşağıda verilen denklemde b1, b2, b3... katsayıları belirlenmiştir (Eşitlik 4). Bu katsayılar kullanılarak 
KOİ ve TÇK giderim değerini maksimum seviyeye getirecek bağımsız parametrelerin alabileceği optimum değerler belirlenmiştir.

$$
\mathrm{Y}=\mathrm{b}_{0}+\mathrm{b}_{1} \mathrm{X}_{1}+\mathrm{b}_{2} \mathrm{X}_{2}+\mathrm{b}_{12} \mathrm{X}_{1} \mathrm{X}_{2}+\mathrm{b}_{13} \mathrm{X}_{1} \mathrm{X}_{3}+\mathrm{b}_{23} \mathrm{X}_{2} \mathrm{X}_{3}+\mathrm{b}_{11} \mathrm{X}_{1}^{2}+\mathrm{b}_{22} \mathrm{X}_{22}^{2}+\mathrm{b}_{33} \mathrm{X}_{3}^{2}
$$

$\mathrm{Bu}$ yönteme göre; $\mathrm{pH}$ değeri, akım yoğunluğu ve elektroliz süresi olmak üzere 3 adet bağımsız değişken için laboratuvardaki ön çalışmalarda elde edilen aralıklar Tablo 2'de görülmektedir.

Tablo 2. Optimizasyon çalışması için proses faktörleri ve seviyeleri

\begin{tabular}{lcccc}
\cline { 3 - 5 } & & \multicolumn{3}{c}{ Seviyeler } \\
\hline Faktörler & Birim & $\mathbf{- 1}$ & $\mathbf{0}$ & $\mathbf{+ 1}$ \\
\hline pH & & 5 & 7 & 9 \\
\hline Akım Yoğunluğu & $\mathrm{A} / \mathrm{m}^{2}$ & 10 & 35 & 60 \\
\hline Elektroliz Süresi & $\mathrm{dk}$. & 10 & 20 & 30 \\
\hline
\end{tabular}

Proseste uygulanan işletme şartlarına göre değişkenlere yanıt değiş̧ken olarak, işlem sonrası numunede KOİ ve TÇK giderim verimleri (\%) belirlenmiştir.

\section{BULGULAR ve TARTIȘMA}

\section{A. EK PROSESI ANALIZZ SONUÇLARI VE ISTATISTIKSEL ANALİŻ}

EK prosesi ile yapılan deneysel çalışmalar sonucunda $\mathrm{pH}$ değerinin $\mathrm{pH} 8$ hariç, diğer tüm deneysel çalışmalarda arttı̆̆ görülmüştür (Tablo 3). Katot elektrottaki suyun indirgenme reaksiyonu sonucunda oluşan hidroksitler atıksu $\mathrm{pH}$ değerini artırmıştır [7]. pH 9 değerinde de bir miktar azalma gözlenmiştir. EK prosesinin atıksu çözeltisini oluşan hidroksitlerden dolayı nötralize etme yeteneğinden kaynaklanmaktadır. İletkenlik değerlerinde de azalma olduğu görülmektedir.

Tablo 3. Deneysel Sonuçlar

\begin{tabular}{|c|c|c|c|c|c|c|c|c|c|c|c|c|c|c|c|c|c|}
\hline No. & 1 & 2 & 3 & 4 & 5 & 6 & 7 & 8 & 9 & 10 & 11 & 12 & 13 & 14 & 15 & 16 & 17 \\
\hline $\mathbf{p H}$ & 9 & 7 & 7 & 7 & 7 & 5 & 7 & 9 & 5 & 7 & 9 & 7 & 5 & 5 & 9 & 7 & 7 \\
\hline A.Y. $\left(A / \mathbf{m}^{2}\right)$ & 35 & 60 & 35 & 10 & 35 & 35 & 60 & 10 & 10 & 10 & 35 & 35 & 35 & 60 & 60 & 35 & 35 \\
\hline E.S. (dk.) & 10 & 30 & 20 & 10 & 20 & 10 & 10 & 20 & 20 & 30 & 30 & 20 & 30 & 20 & 20 & 20 & 20 \\
\hline Potansiyel Fark (V) & 8,8 & 14 & 9 & 3,8 & 8,9 & 9,8 & 14 & 4 & 3 & 3,7 & 11 & 9 & 8,7 & 16 & 13 & 9 & 9 \\
\hline $\mathrm{pH}_{\mathrm{s}}$ & 8,45 & 8,74 & 7,64 & 7,22 & 7,57 & 7,5 & 7,8 & 8,18 & 6,27 & 7,4 & 9,22 & 7,64 & 6,32 & 6,15 & 8,5 & 7,6 & 7,62 \\
\hline E. $\dot{I}_{i}(\mathrm{mS} / \mathrm{cm})$ & 7,65 & 7,65 & 7,65 & 7,65 & 7,65 & 7,65 & 7,65 & 7,65 & 7,65 & 7,65 & 7,65 & 7,65 & 7,65 & 7,65 & 7,65 & 7,65 & 7,65 \\
\hline E. $\dot{I}_{\text {ss }}(\mathrm{mS} / \mathrm{cm})$ & 5,86 & 3,4 & 4,86 & 5,5 & 4,8 & 6,11 & 5,4 & 5,96 & 6,64 & 5,7 & 4,41 & 4,88 & 5,1 & 2,23 & 4,66 & 4,84 & 4,86 \\
\hline
\end{tabular}

A.Y.:Akım Yoğunluğu, E.S.: Elektroliz Süresi, $\mathrm{pH}_{\mathrm{s}}$ : Son pH, E.İ.i İletkenlik

EK prosesinin optimizasyonu için $\mathrm{pH}$, akım yoğunluğu ve elektroliz süresi gibi işletme parametrelerinin etkisi araştırılmıştır. Optimizasyon sonucu ANOVA analizi Tablo 4'te verilmiştir. İstatistiksel analiz sonucunda quadratik modele uyum sağladığı belirlenmiştir. Quadratik model için elde edilen verilere göre etkin parametreler, $\mathrm{p}<0.05$ değerlerine göre değerlendirmiştir. Buna göre, 
$(p<0.05)$ kimyasal sprey atıksuyundan EK prosesi ile KOİ ve TÇK giderim veriminde akım yoğunluğu ve elektroliz süresinin oldukça önemli olduğu belirlenirken, $\mathrm{pH}$ parametresinin diğer iki parametreye göre daha az öneme sahip olduğu görülmüştür. Burada $\mathrm{pH}$ değeri, akım yoğunluğu ve elektroliz süresi parametrelerinin artmasıyla birlikte çözünen elektrot materyali ve oluşan hidroksitlerden dolayı $\mathrm{pH}$ değeri nötral/bazik aralıkta kalmıştır. Bu nedenle $\mathrm{pH}$ değeri asidik olsa bile elektroliz prosesi sonucundan $\mathrm{pH}$ değeri nötral ve bazik seviyelere gelmiştir.

EK reaktöründe KOİ ve TÇK'nın giderilmesi için regrasyon $\left(R^{2}\right)$ değerinin sırasıyla 0,95 ve 0,$99 ; R^{2}$ adj değerinin sirasıyla 0,88 ve 0,99 olduğu bulunmuştur. $R^{2}$ ve $R_{\text {adj }}^{2}$ değerlerinin 1 'e yakın olmasi, deney sonuçlarının ve istatistiksel çıkarımların uyumlu olduğunu ve işlem parametrelerinin etkilerinin belirlenmesinde Box-Behnken istatistiksel tasarımının etkili olduğu tespit edilmiştir.

Tablo 4. ANOVA Analizi

\begin{tabular}{|c|c|c|c|c|c|c|c|c|}
\hline \multirow[b]{2}{*}{ Source } & \multicolumn{4}{|c|}{ KOİ Giderim Verimi } & \multicolumn{4}{|c|}{ TÇK Giderim Verimi } \\
\hline & $\begin{array}{c}\text { Sum of } \\
\text { Squares }\end{array}$ & $\begin{array}{c}\text { Mean } \\
\text { Square }\end{array}$ & $\begin{array}{c}\mathbf{F} \\
\text { Value }\end{array}$ & $\begin{array}{l}\text { p-value } \\
\text { Prob }>\text { F }\end{array}$ & $\begin{array}{c}\text { Sum of } \\
\text { Squares }\end{array}$ & $\begin{array}{c}\text { Mean } \\
\text { Square }\end{array}$ & $\begin{array}{c}\text { F } \\
\text { Value }\end{array}$ & $\begin{array}{c}\text { p-value } \\
\text { Prob > F }\end{array}$ \\
\hline Model & 0,037 & 4,164E-003 & 13,76 & 0,0011 & 0,16 & 0,018 & 128,99 & $<0.0001$ \\
\hline A-pH & $2,007 \mathrm{E}-003$ & $2,007 \mathrm{E}-003$ & 6,63 & 0,0367 & $9,602 \mathrm{E}-004$ & $9,602 \mathrm{E}-004$ & 6,95 & 0,0336 \\
\hline B-A.Y. & 0,021 & 0,021 & 68,15 & $<0.0001$ & 0,10 & 0,10 & 732,54 & $<0.0001$ \\
\hline C-E.S. & 0,010 & 0,010 & 34,47 & 0,0006 & 0,019 & 0,019 & 138,66 & $<0.0001$ \\
\hline $\mathrm{AB}$ & $1,045 \mathrm{E}-004$ & $1,045 \mathrm{E}-004$ & 0,35 & 0,5753 & $3,376 \mathrm{E}-003$ & $3,376 \mathrm{E}-003$ & 24,45 & 0,0017 \\
\hline $\mathrm{AC}$ & $9,213 \mathrm{E}-005$ & $9,213 \mathrm{E}-005$ & 0,30 & 0,5982 & $1,978 \mathrm{E}-003$ & $1,978 \mathrm{E}-003$ & 14,32 & 0,0068 \\
\hline $\mathrm{BC}$ & $1,127 \mathrm{E}-003$ & $1,127 \mathrm{E}-003$ & 3,72 & 0,0950 & $7,276 \mathrm{E}-003$ & $7,276 \mathrm{E}-003$ & 52,70 & 0,0002 \\
\hline $\mathrm{A}^{2}$ & 5,104E-005 & 5,104E-005 & 0,17 & 0,6936 & 0,024 & 0,024 & 173,65 & $<0.0001$ \\
\hline $\mathrm{B}^{2}$ & $2,099 \mathrm{E}-003$ & $2,099 \mathrm{E}-003$ & 6,94 & 0,0337 & $1,966 \mathrm{E}-007$ & $1,966 \mathrm{E}-007$ & $1,424 \mathrm{E}-003$ & 0,9710 \\
\hline $\mathrm{C}^{2}$ & $8,333 \mathrm{E}-004$ & $8,333 \mathrm{E}-004$ & 2,75 & 0,1410 & $1,602 \mathrm{E}-003$ & $1,602 \mathrm{E}-003$ & 11,60 & 0,0113 \\
\hline Residual & $2,118 \mathrm{E}-003$ & $3,026 \mathrm{E}-004$ & & & $9,665 \mathrm{E}-004$ & $1,381 \mathrm{E}-004$ & & \\
\hline $\begin{array}{r}\text { Lack of } \\
\text { Fit }\end{array}$ & $1,904 \mathrm{E}-003$ & $6,345 \mathrm{E}-004$ & 11,84 & 0,0186 & $9,445 \mathrm{E}-004$ & $3,148 \mathrm{E}-004$ & 57,13 & 0,0010 \\
\hline Pure Er. & 2,144E-004 & 5,360E-005 & & & 2,204E-005 & 5,511E-006 & & \\
\hline $\begin{array}{r}\text { Cor } \\
\text { Total }\end{array}$ & 0,040 & & & & 0,16 & & & \\
\hline & $\begin{array}{r}\text { R-Squared } \\
\text { Adj R-Squared }\end{array}$ & $\begin{array}{l}0,9465 \\
0,8777\end{array}$ & & & $\begin{array}{r}\text { R-Squared } \\
\text { Adj R-Squared }\end{array}$ & $\begin{array}{l}0,9940 \\
0,9863\end{array}$ & & \\
\hline
\end{tabular}

Deneysel tasarım sonunda elde edilen eşitlikler Tablo 5’te görülmektedir.

Tablo 5. KOİ ve TÇK Giderimi için elde edilen eşitlikler

\begin{tabular}{|c|c|c|c|}
\hline $\begin{array}{l}\text { KOI Giderim } \\
\text { Verimi }\end{array}$ & $=$ & $\begin{array}{r}\text { TÇK Giderim } \\
\text { Verimi }\end{array}$ & $=$ \\
\hline+0.65 & & +0.37 & \\
\hline-0.016 & $* \mathrm{pH}$ & +0.011 & $* \mathrm{pH}$ \\
\hline+0.051 & * A.Y. & +0.11 & * A.Y. \\
\hline+0.036 & * E.S. & +0.049 & $*$ E.S. \\
\hline$+5.110 \mathrm{E}-003$ & $* \mathrm{pH}^{*} \mathrm{~A} . \mathrm{Y}$. & -0.029 & $* \mathrm{pH} * \mathrm{~A} . \mathrm{Y}$. \\
\hline$+4.799 \mathrm{E}-003$ & $*$ pH $*$ E.S. & -0.022 & $*$ pH $*$ E.S. \\
\hline+0.017 & $*$ A.Y. * E.S. & +0.043 & $*$ A.Y. ${ }^{*}$ E.S \\
\hline$+3.482 \mathrm{E}-003$ & $* \mathrm{pH}^{2}$ & -0.075 & $* \mathrm{pH}^{2}$ \\
\hline-0.022 & $*$ A.Y. $^{2}$ & $+2.161 \mathrm{E}-004$ & $*$ A.Y. ${ }^{2}$ \\
\hline-0.014 & $*$ E.S. $^{2}$ & -0.020 & $*$ E.S. $^{2}$ \\
\hline
\end{tabular}


Şekil 4'te EK prosesi ile KOİ ve TÇK gideriminde elde edilen deneysel sonuçlar ve modelin tahminlediği sonuçlar görülmektedir.
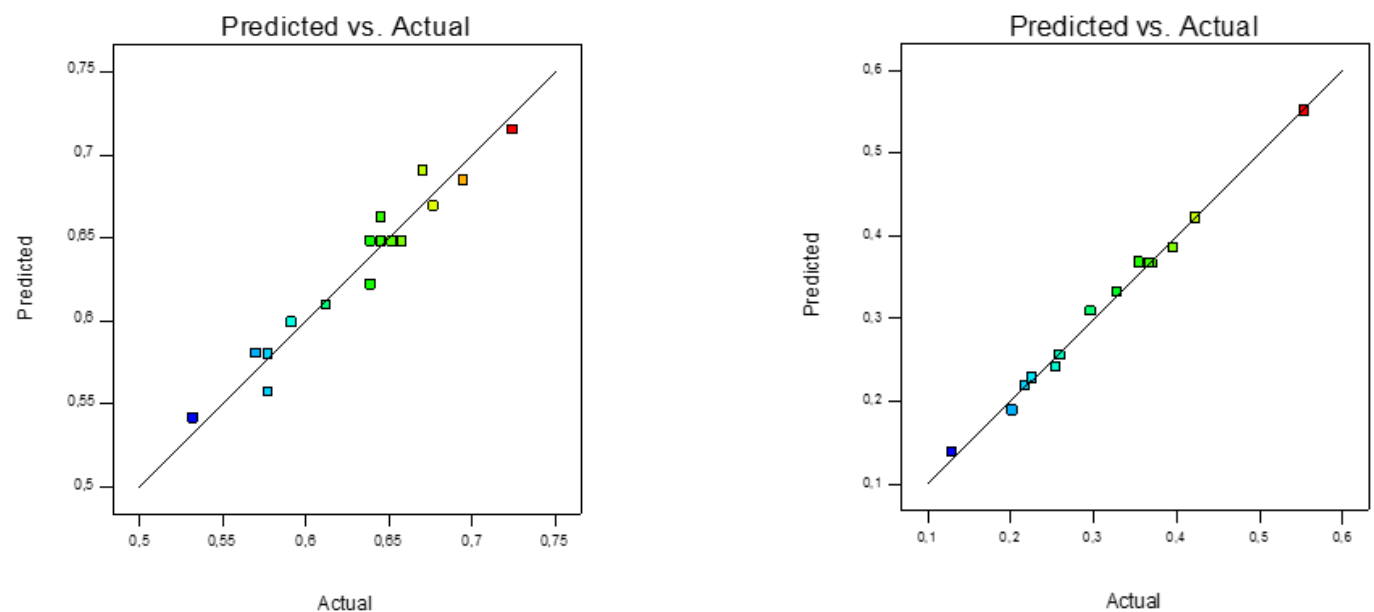

Şekil 4. Deneysel Çalışmalarda Elde Edilen ve Modelin Tahminlediği Veriler a) KOI Giderimi b) TÇK Giderimi

Şekil 5'te EK prosesi ile KOİ giderimindeki optimum şartlar, Şekil 6'da TÇK giderimindeki optimum şartlar görülmektedir.

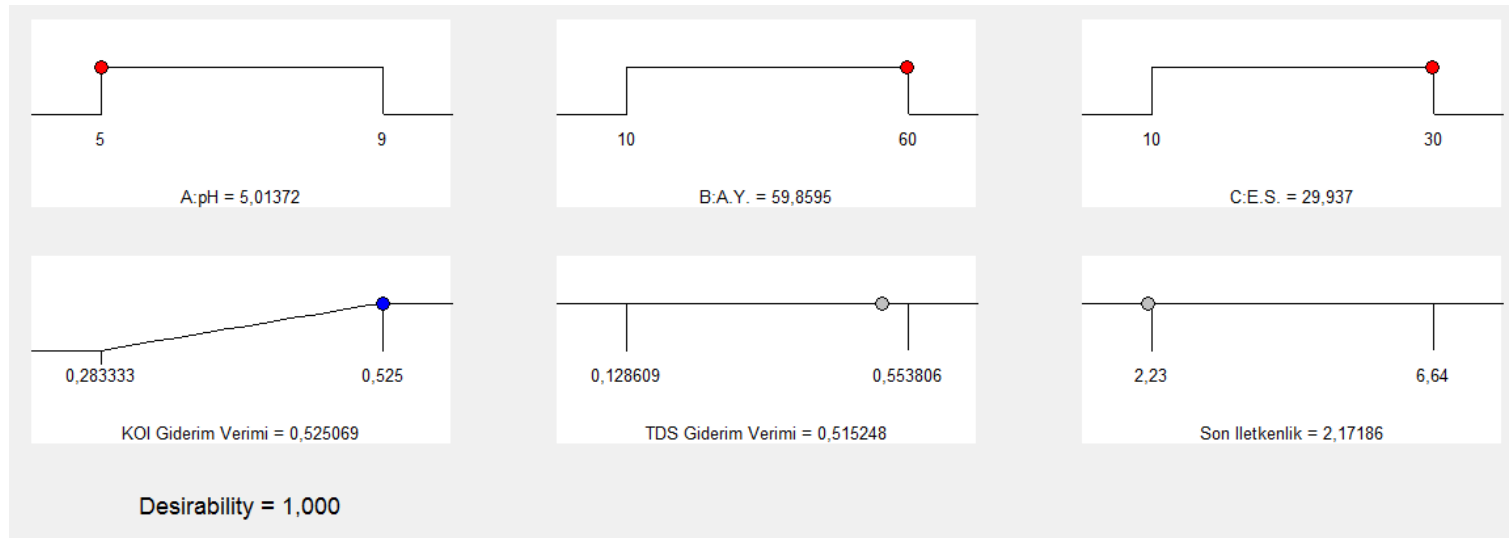

Şekil 5. KOİ giderimi için optimum şartlar

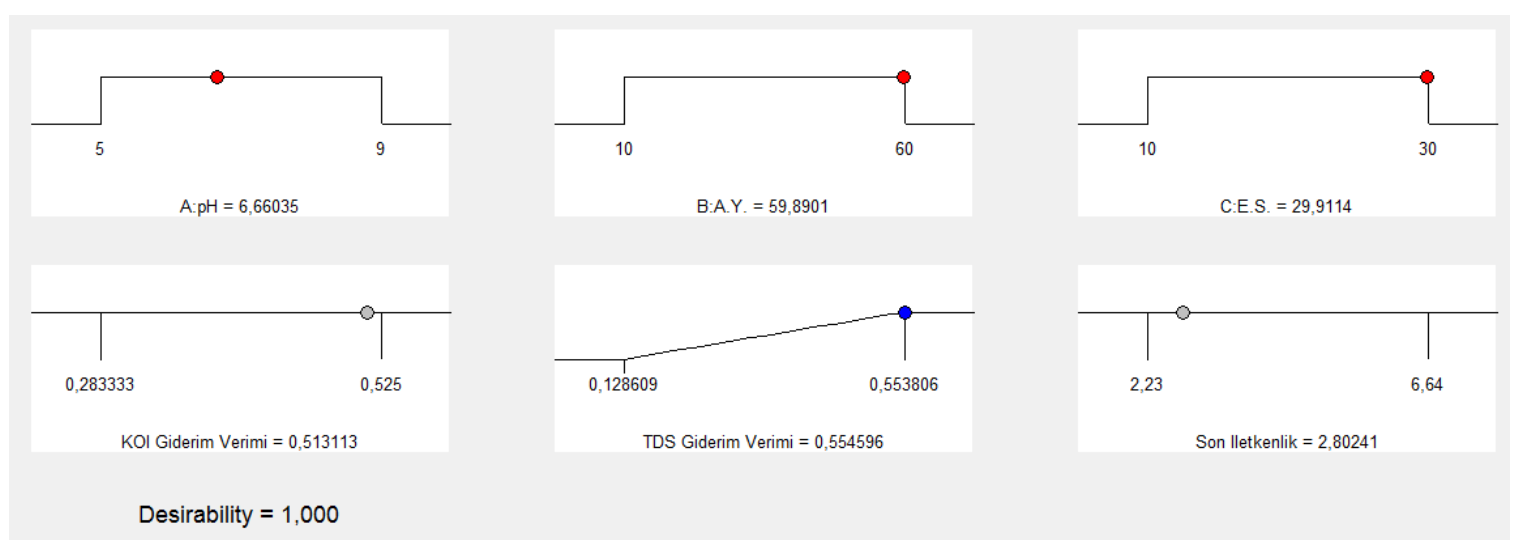

Şekil 6. TÇK giderimi için optimum şartlar 
pH ve akım yoğunluğu parametreleri EK prosesi ile kirletici gideriminde önemli rol oynamaktadır [7]. Atıksu içerisinde düşük $\mathrm{pH}$ değerlerinde $\mathrm{Al}^{3+}$ ve $\mathrm{Al}(\mathrm{OH})_{2}{ }^{+}$gibi katyonik monomerik $\mathrm{Al}$ türleri mevcuttur. pH değeri 4-9 aralığında $\mathrm{Al}(\mathrm{OH})_{2}$ gibi monomerik bileşikler, $\mathrm{Al}_{6}(\mathrm{OH})_{15}{ }^{3+}$ gibi polimerik bileşikler kompleks polimerizasyon ve/veya presipitasyon mekanizması ile çözünmez amorf $\mathrm{Al}(\mathrm{OH})_{3(\mathrm{~s})}$ floğuna dönüşür. $\mathrm{pH}$ değeri 8 'den büyük olması durumunda monomerik $\mathrm{Al}(\mathrm{OH})_{4}$ konsantrasyonu artar, çözünmez amorf $\mathrm{Al}(\mathrm{OH})_{3(\mathrm{~s})}$ floğunun miktarını azaltır [8].

Akım yoğunluğu parametresi koagülant oluşum hızını, kabarcık üretimini düzenlemesi, flok büyümesini ve bunlara bağlı olarak EK prosesinin reaksiyon hızını etkilemesinden dolayı en önemli parametredir [7;9]. Şekil 7'de görüldüğü üzere, akım yoğunluğunun artmasıyla KOİ giderim verimi artmıştır. Akım yoğunluğu atıksu ortamında salınan elektrot materyalini de artırarak süpürme etkisiyle kirleticilerin daha kolay giderilmesini sağlamaktadır. Akım yoğunluğunun KOİ ve TÇK gideriminde oldukça etkin parametre olduğu görülmektedir. Akım yoğunluğunun artmasıyla KOİ, renk gideriminin arttığı da literatürdeki çalışmada belirtilmiştir [7].

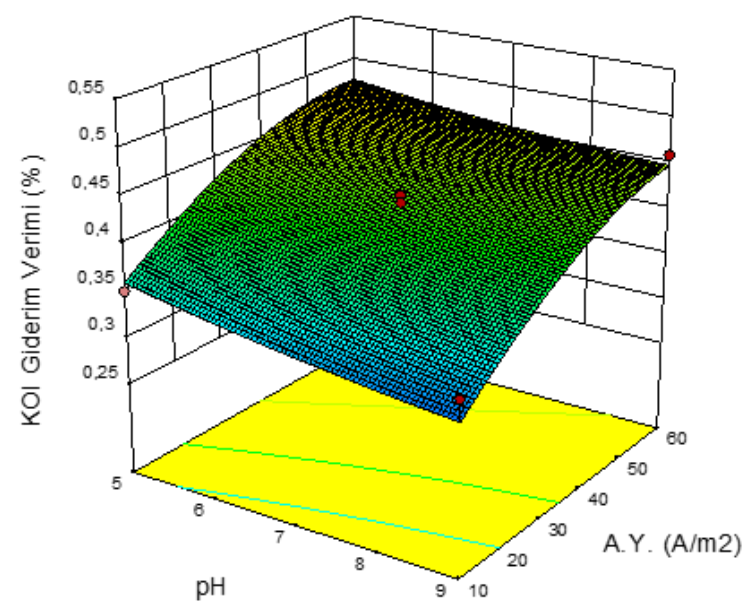

a)

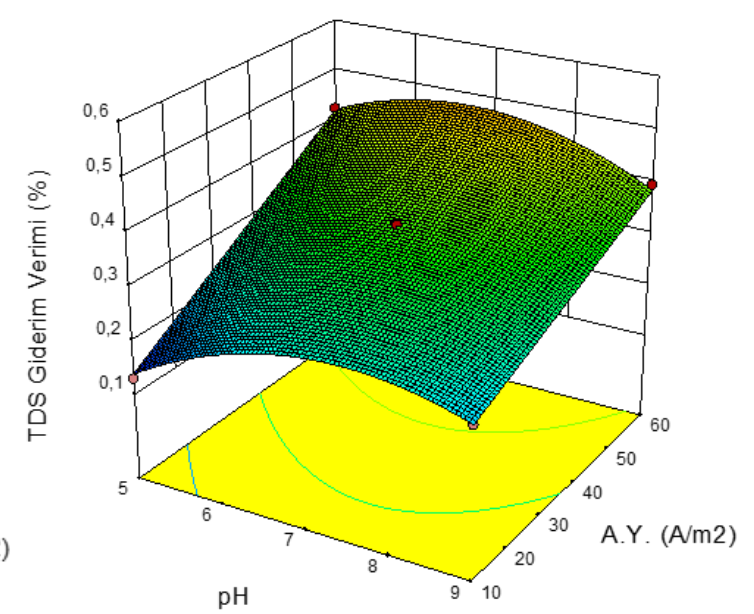

b)

Şekil 7. Elektroliz Süresinin 20 dk. olduğu deney şartlarında pH ve Akım Yoğunluğunun Etkisi a) KOI Giderim Verimi b) TÇK Giderim Verimi

\section{C. pH ve ELEKTROLIZ SÜRESINIIN KOİ/TÇK GIDERIM VERIMINE ETKISII}

pH ve elektroliz süresi parametrelerinin KOİ giderim verimine etkisine bakıldığında, $\mathrm{pH}$ değerinin çok büyük etkisi olmazken, elektroliz süresi daha etkin bir parametredir. Ancak elektroliz süresinin artmasıyla KOİ giderim verimi anlamlı şekilde artmamıştır (Şekil 8a). TÇK giderim verimi açısından bakıldığında ise, $\mathrm{pH}$ parametresinin elektroliz süresine göre daha etkin parametre olduğu görülmektedir (Şekil 8b). 


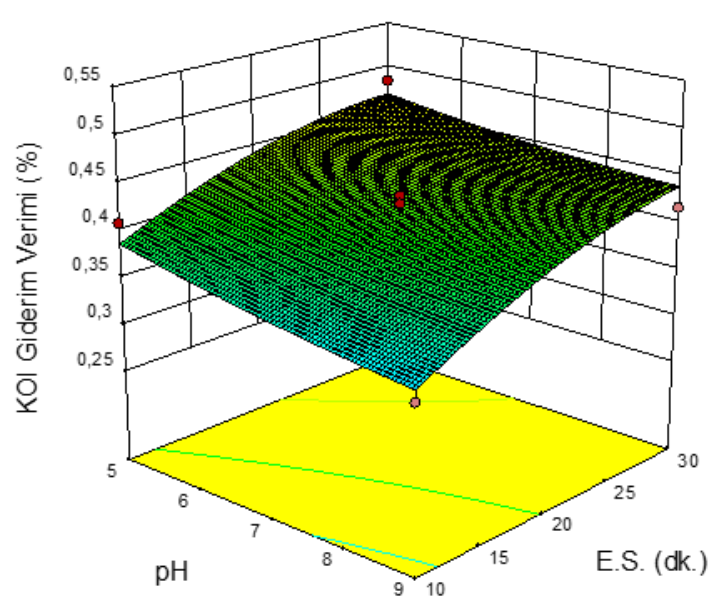

a)

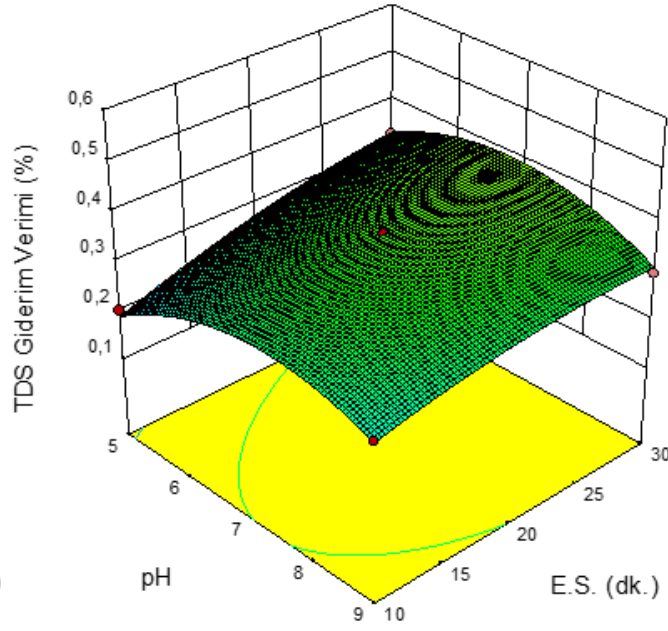

b)

Şekil 8. Akım Yoğunluğunun $35 \mathrm{~A} / \mathrm{m}^{2}$ olduğu deney şartlarında pH ve Elektroliz Süresinin Etkisi a) KOİ Giderim Verimi b) TÇK Giderim Verimi

\section{AKIM YOĞUNLUĞU VE ELEKTROLIZ SÜRESININ KOİ/TÇK GIDERIM VERIMIINE ETKISİ}

Akım yoğunluğu Al iyonu çözünme hızını artırdığından EK prosesinde önemli bir parametredir [10]. $\mathrm{Bu}$ çalışmada da akım yoğunluğu ve elektroliz süresinin KOİ giderim veriminde önemli iki parametre olduğu belirlenmiştir (Şekil 9a). Yüksek akım yoğunluğu ve yüksek elektroliz süresinde en yüksek KOİ giderim verimi elde edilmiştir. Aynı trend TÇK giderim verimi açısından da gözlenmiştir (Şekil 9b).

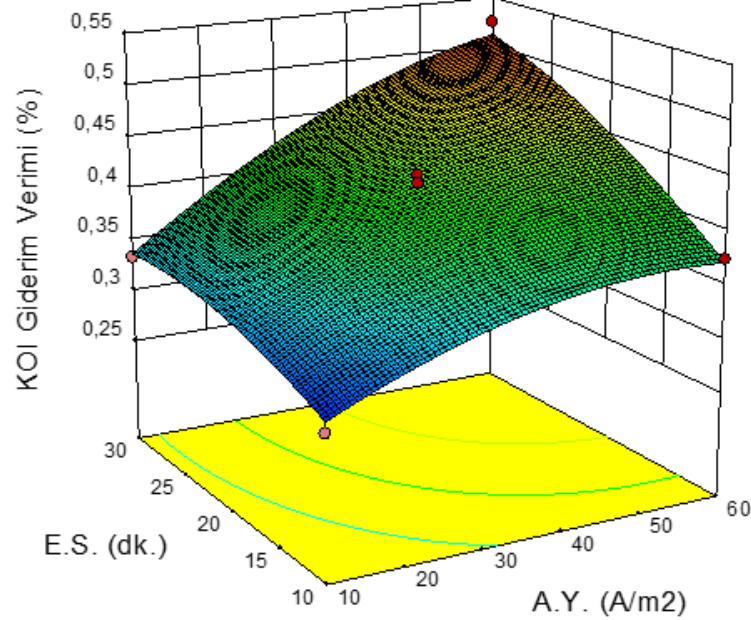

a)

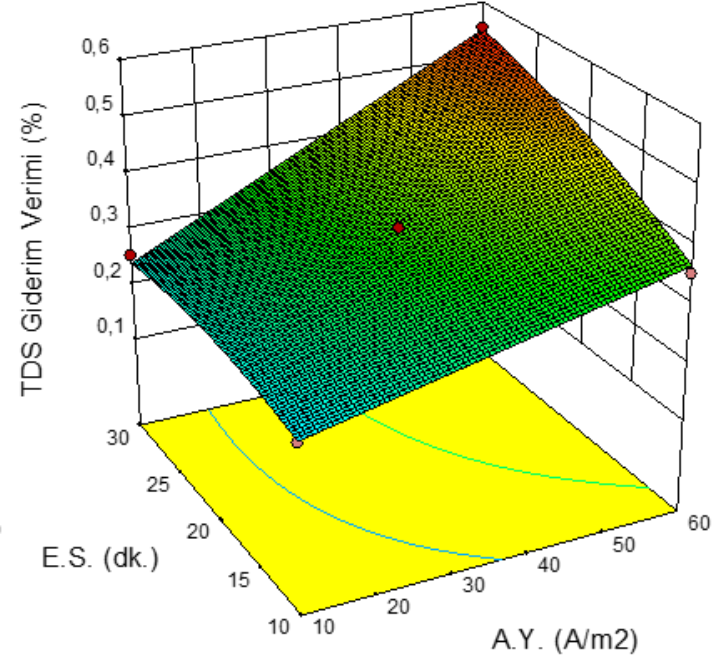

b)

Şekil 9. pH değerinin 7 olduğu deney şartlarında Akım Yoğunluğu ve Elektroliz Süresinin Etkisi a) KOİ Giderim Verimi b) TÇK Giderim Verimi 


\section{SONUC}

Çalışmada, elektrot materyali olarak Al elektrodunun kullanıldığ Elektrokoagülasyon (EK) Prosesi ile kot pantolon üretim sürecinde kimyasal spreyleme prosesi atıksularının arıtımı üzerine yapılan çalışmada akım yoğunluğu ve elektroliz süresinin $\mathrm{pH}$ değerine göre daha etkin parametre olduğu tespit edilmiştir. EK reaktöründe KOİ ve TÇK'nın giderilmesi için regrasyon $\left(\mathrm{R}^{2}\right)$ değerinin sırasıyla 0,95 ve 0,99; Adj $R^{2}$ değerinin sırasıyla 0,88 ve 0,99 olduğu bulunmuştur. $R^{2}$ ve $R^{2}$ adj değerlerinin 1'e yakın olması, deney sonuçlarının ve istatistiksel çıkarımların uyumlu olduğunu ve işlem parametrelerinin etkilerinin belirlenmesinde Box-Behnken istatistiksel tasarımının etkili olduğunu göstermiştir. En yüksek KOİ ve TÇK giderimleri (>\%50) için optimum pH değerleri sırasılla 5,01 ve 6,66 olarak tespit edilirken, her iki kirletici için optimum akım yoğunluğu $59 \mathrm{~A} / \mathrm{m}^{2}$ ve elektroliz süresi $29 \mathrm{dk}$. olarak belirlenmiştir. Atıksuyun EK prosesi ile arıtımı sonrası elde edilen pH değerleri deşarj standartları olan 6-9 aralığında elde edilmiştir. EK prosesi sonrası atıksu pH değeri herhangi ayarlamaya gerek kalmaksızın deşarj edilebilir niteliktedir.

\section{KAYNAKLAR}

[1] E. GilPavasa, I. Dobrosz-Gómez, M. Á. Gómez-Garcíac, "Optimization of sequential chemical coagulation - electro-oxidation process for the treatment of an industrial textile wastewater," Journal of Water Process Engineering, vol. 22, pp. 73-79, 2018.

[2] A. Kumar, P.V. Nidheesh, M.S. Kumar, "Composite wastewater treatment by aerated electrocoagulation and modified peroxi-coagulation processes," Chemosphere, vol. 205, pp. 587-593, 2018.

[3] E. Güneş, E. Demir, Y. Güneş, A. Hanedar, "Characterization and treatment alternatives of industrial container and drum cleaning wastewater: Comparison of Fenton-like process and combined coagulation/oxidation processes," Separation and Purification Technology, vol. 209, pp. 426-433, 2019.

[4] A. D. Barbosa, L.F.d. Silva, H. M. de Paula, L. L. Romualdo, G. Sadoyama, L.S. Andrade, "Combined use of coagulation (M. oleifera) and electrochemical techniques in the treatment of industrial paint wastewater for reuse and/or disposal," Water Research, vol.145, pp. 153-161, 2018.

[5] Chen, X., Chen, G.C., Yue, P.L., "Separation of Pollutants from Restaurant Wastewater by Electrocoagulation," Seperation and Purification Technology, vol. 19, pp. 65-76. 2000.

[6] APHA, American Public Health Association (APHA), Standard Methods for the Examination of Waste and Wastewater (19th ed.), Washington. 2005.

[7] A.K. Verma, "Treatment of textile wastewaters by electrocoagulation employing Fe-Al composite electrode," Journal of Water Process Engineering, vol. 20, pp. 168-172, 2017.

[8] K. Merzouk, A. Madani, "Using electrocoagulation-electroflotation technology to treat synthetic solution and textile wastewater, two case studies," Desalination, vol. 250, pp. 573-577, 2010. 
[9] M. Kobya, E. Demirbas, "Evaluations of operating parameters on treatment of can manufacturing wastewater by electrocoagulation," Journel Water Process Engineering, vol. 8, pp. 6474, 2015.

[10] C.J. Nawarkar, V.D. Salkar, "Solar powered Electrocoagulation system for municipal wastewater treatment," Fuel, vol. 237, pp. 222-226, 2019. 